\title{
Egg Production in Poultry Farming Is Improved by Probiotic Bacteria
}

\author{
Juan Manuel Peralta-Sánchez ${ }^{1 * t}$, Antonio Manuel Martín-Platero ${ }^{2 * t}$, \\ Juan José Ariza-Romero ${ }^{3}$, Miguel Rabelo-Ruiz' ${ }^{2}$, María Jesús Zurita-González ${ }^{3}$, \\ Alberto Baños ${ }^{3}$, Sonia María Rodríguez-Ruano ${ }^{2,4}$, Mercedes Maqueda ${ }^{2}$, Eva Valdivia ${ }^{2,5}$ \\ and Manuel Martínez-Bueno ${ }^{2,5}$
}

${ }^{1}$ Estación Biológica de Doñana - Consejo Superior de Investigaciones Científicas, Seville, Spain, ${ }^{2}$ Departamento de Microbiología, Universidad de Granada, Granada, Spain, ${ }^{3}$ Departamento de Microbiología y Biotecnología - DMC Research Center, Granada, Spain, ${ }^{4}$ Faculty of Science, University of South Bohemia, České Budějovice, Czechia, ${ }^{5}$ Instituto de Biotecnología, Universidad de Granada, Granada, Spain

Antimicrobial resistance (AMR) is one of the most serious threats for human health in the near future. Livestock has played an important role in the appearance of antibioticresistant bacteria, intestinal dysbiosis in farming animals, or the spread of AMR among pathogenic bacteria of human concern. The development of alternatives like probiotics is focused on maintaining or improving production levels while diminishing these negative effects of antibiotics. To this end, we supplied the potential probiotic Enterococcus faecalis UGRA10 in the diet of laying hens at a final concentration of $10^{8}$ Colony Forming Units per gram (CFU/g) of fodder. Its effects have been analyzed by: (i) investigating the response of the ileum and caecum microbiome; and (ii) analyzing the outcome on eggs production. During the second half of the experimental period (40 to 76 days), hens fed $E$. faecalis UGRA10 maintained egg production, while control animals dropped egg production. Supplementation diet with $E$. faecalis UGRA10 significantly increased ileum and caecum bacterial diversity (higher bacterial operational taxonomic unit richness and Faith's diversity index) of laying hens, with animals fed the same diet showing a higher similarity in microbial composition. These results point out to the beneficial effects of E. faecalis UGRA10 in egg production. Future experiments are necessary to unveil the underlying mechanisms that mediate the positive response of animals to this treatment.

Keywords: bacterial community, egg production, Enterococcus faecalis UGRA10, high-throughput sequencing, laying hens, probiotics

\section{INTRODUCTION}

The emergence of antimicrobial resistance (AMR) is a worldwide issue in public health (Ferri et al., 2017; World Health Organization, 2018). This situation has been reached due to the abusive prescription of antibiotics, their inappropriate use by patients, and the abuse of these substances in livestock (Hecker et al., 2003; Levy and Marshall, 2004; Capita and Alonso-Calleja, 2013). The indiscriminate use of antibiotics in livestock is due to two major reasons. The first and most obvious one is disease control associated with intensive farming and animal overcrowding (McEwen and Fedorka-Cray, 2002; Gilchrist et al., 2007; Marshall and Levy, 2011). The second reason is the discovery of the effects of antibiotics as growth promoters (AGPs, reviewed in McEwen and Fedorka-Cray, 2002; Dibner and Richards, 2005). Although the mechanisms of action are still unclear, antibiotic imbalance alters the bacterial communities of the intestine, causes alterations 
in the digestive tract and in the metabolic processes, and increases nutrient absorption (Dibner and Richards, 2005; Miles et al., 2006; Niewold, 2007). In addition, antibiotics affect the immune system, via changes in bacterial community or directly altering the immune response (Bode et al., 2014; Yang et al., 2017). Therefore, one of the bacterial communities most affected by the use of antibiotics is the intestinal microbiome (McEwen and Fedorka-Cray, 2002; Wegener, 2003). These bacteria play a fundamental role in gut homeostasis, balance, and resilience (Clemente et al., 2012; Huttenhower et al., 2012). However, the appearance of undesirable collateral effects, especially affecting the distribution and selection of AMR genes in commensal bacteria, makes these bacteria risky to human health (Wegener, 2003) and makes it necessary to search alternatives to the use of antibiotics in livestock (Ferket, 2004).

Antibiotics have played a major role in maximizing poultry production (McEwen and Fedorka-Cray, 2002; Dibner and Richards, 2005). Thus, they have been used as growth promoters in broilers (Gadde et al., 2018; Wealleans et al., 2018), or egg production enhancers in laying hens (Park et al., 2016). This increase in productivity has been associated with the beneficial role of antibiotics in infection control in poultry farms (Gustafson and Bowen, 1997; McEwen and FedorkaCray, 2002; Singer and Hofacre, 2006). However, undesirable and collateral effects have appeared, especially affecting changes in the distribution and selection of AMR genes in commensal bacteria (Teuber, 2001; Diarra et al., 2007; Diarrassouba et al., 2007; Gyles, 2008). Some evidences point out the appearance of AMR in relation to the use of antibiotics in poultry. The relationship between the use of fluoroquinolones and AMR in Campylobacter sp. has been evidenced (Alfredson and Korolik, 2007; Nelson et al., 2007). Multi-resistant strains of Escherichia coli have been associated with avian farms and have been found in chicken-derived products (Diarra et al., 2007; Diarrassouba et al., 2007; Thibodeau et al., 2007; Gyles, 2008; Osman et al., 2018). Several studies pointed out poultry and derivate-food as a reservoir and potential resource for Salmonella sp. resistant strains (Carramiñana et al., 2004; de Oliveira et al., 2005; Singh et al., 2010; Velasquez et al., 2018). Under this scenario of AMR, governments and institutions started to ban the use of antibiotics in livestock (European Commission, 2003, 2005; U.S. FDA, 2017). However, the prohibition of antibiotics in livestock in general, and in the poultry sector in particular, has caused an increase in incidence of infectious diseases by Campylobacter jejuni or Clostridium perfringens (reviewed in Van Immerseel et al., 2004; Alfredson and Korolik, 2007). Therefore, there is considerable concern and a certain need to replace antibiotics in disease control and as growth promoters (Joerger, 2003; Griggs and Jacob, 2005).

Different agents have been suggested to substitute antibiotics in poultry farming, such as prebiotics and probiotics (Patterson and Burkholder, 2003; Gaggia et al., 2010). Most probiotics used in aviculture are bacteria that already exist in the digestive tract of animals and have properties of interest as signal modulators of intestinal cells, bacterial community stabilizers or competitors against undesirable bacterial species (de Vrese and Schrezenmeir, 2008; Kabir, 2009). Although Enterococcus species are not "generally recognized as safe" (GRAS, reviewed in Ogier and Serror, 2008), different Enterococcus species have been tested as probiotics (Fuller, 1989; Franz et al., 2011). The use of enterococci as probiotics remains controversial: while the probiotic benefits of some strains have been well-established, the increase in enterococcal diseases associated with human health and resistance to multiple antibiotics has raised concerns about their use (Franz et al., 2003). Despite this controversy, some strains are commercialized as probiotics, such as Enterococcus faecium SF68 (Cylactin, F. Hoffmann-Roche, S.A., Switzerland) and Enterococcus faecalis (Symbioflor, SymbioPharm, Germany) (Habermann et al., 2001; Fenimore et al., 2017; TorresHenderson et al., 2017). E. faecalis has been pointed out as a potential substitute for antibiotics (Gaggia et al., 2010). E. faecalis is a common bacterium in vertebrate gut, Gram+, facultative anaerobe, with a high degree of tolerance to $\mathrm{pH}(3-10)$ and salinity [6.5\% $\mathrm{NaCl}(\mathrm{w} / \mathrm{v})]$ (Krieg and Holt, 1984; Schleifer and Kilpper-Bälz, 1984) which would allow gastrointestinal transit to the large intestine. Moreover, they are good producers of antagonistic substances, especially bacteriocins, also called enterocins, which allow a great interaction with the rest of the community (Foulquie-Moreno et al., 2006; Martín-Platero et al., 2006; Trmcic et al., 2011). In this sense, the strain E. faecalis UGRA10 isolated from an Andalusian goat cheese is a producer of the enterocin AS-48 and has very interesting technological properties: it is resistant to high concentrations of bile [up to $40 \%$ $(\mathrm{w} / \mathrm{v})$ ]; shows a high antagonistic spectrum including Gram- and Gram+ bacteria (Cebrian et al., 2012) and seems to stimulate immune response in animals (Baños, 2016). Interestingly, this strain is harmless to mice and fish, and protects against some pathogenic strains such as C. perfringens in mice and Lactococcus garvieae in rainbow trout and zebrafish (Baños, 2016). These properties make E. faecalis UGRA10 an excellent candidate for probiotic and a model to test its implantation, its effects on the community and, especially, on health and production of animals.

We investigated the possible influence of E. faecalis UGRA10 on egg production and gut microbiome of laying hens when administered in the diet, combining the classical culture techniques with the latest high throughput sequencing.

\section{MATERIALS AND METHODS}

\section{Laying Hens and Farm Facilities}

The experiment was performed at Granja Avícola Gil, SL, a laying hen farm (Alhendín, Granada, Spain). Laying hens were kept at $20 \pm 2{ }^{\circ} \mathrm{C}$ and $78 \pm 3 \%$ relative humidity (average \pm standard deviation), under a photoperiod of $16 \mathrm{~h}$ per day. The farm fulfilled the national regulations and the European directive for the protection of animal welfare in research (Directive 2010/63/EU, European Commission, 2010).

\section{Experimental Design and Sampling Collection}

Three production lines housed 180 experimental laying hens in groups of 6 hens per cage, with food and water ad libitum. All laying hens belonged to the same Hy Line brown variety and were 
placed in cages at the age of 16 weeks. Cage distribution between treatment groups was randomly assigned in three production lines. Hens were kept and fed during 2 weeks for acclimation.

Control hens (90 hens, 15 cages) received a basal fodder diet ( $45 \%$ fish flour, $35 \%$ soya, $8 \%$ granulated corn, $7 \%$ bran corn, and $5 \%$ sunflower bread) while experimental hens (90 hens, 15 cages) received the same diet but supplemented with the bacterium E. faecalis UGRA10 (see below).

Hens were first kept at the farm for 15 days for acclimation. Experiment started on April $8^{\text {th }}$, and egg production (number of eggs) of each treatment group was recorded every working day until the day 76. At this experimental farm, laying hens are slaughtered after 76 days. One day per week, eggs from each treatment were weighted and classified into size categories (S: <53 g; M: 53-63 g; L: 63-73 g; XL; >73 g) according to EU regulation (European Commission, 2008). Fecal samples were collected on days $7,15,40$, and 76 of the experiment. On day 40, 13 hens of each group, they were euthanized by an intrathoracic injection of $2 \mathrm{~mL} / \mathrm{hen}$ of the euthanasic T-61 (Intervet, Salamanca, Spain). On day 76, 10 hens from each group were euthanized following similar procedure. Immediately after slaughtering, hens were dissected and ileum and caecum were collected with sterile material, kept in sterile plastic bags, and transported directly to the lab where samples were processed. No animal died during the experimental period due to illness or malnutrition.

\section{E. faecalis UGRA10 Production}

Enterococcus faecalis UGRA10 was isolated by the Microbial Antagonism research group from the University of Granada (Cebrian et al., 2012). The bacteria were cultured in bioreactors in the DMC Research facilities located in Alhendín (Granada, Spain), as by-product of AS-48 bacteriocin production. Briefly, the strain was cultured from $-80^{\circ} \mathrm{C}$ stock in Tryptic Soy Agar (Scharlau, S.L., Spain) and isolated colonies were inoculated into 2 L Brain Heart Infusion broth (BHI, Scharlau, S.L., Spain) and incubated at $28^{\circ} \mathrm{C}$ for $24 \mathrm{~h}$. This primary inoculum was added (5\%) to a broth based on Lactoalbumin Esprion 300 (E-300, DMW International, Holland) as described in Ananou et al. (2008) in a $20 \mathrm{~L}$ biofermenter (Biobech 20 Applikon Biotechnology, Delft, Netherlands), and then incubated at $28^{\circ} \mathrm{C}$ for $24 \mathrm{~h}$. Afterward, $16 \mathrm{~L}$ of this culture were added of a $300 \mathrm{~L}$ of Lactoalbumin Esprion 300 in a CHEMAP fermenter (Compact Unit, Process Engineering Company, India) and incubated at $29^{\circ} \mathrm{C}$ for $24 \mathrm{~h}$. All inocula and broths were adjusted at $\mathrm{pH}$ 6.5. Cells were collected by means of aM-500 ultrafiltration equipment (BionetIngenieria, Spain). Afterward, cells were suspended in saline buffer and re-centrifuged twice. Final clean pellets were kept at $-20^{\circ} \mathrm{C}$.

Cells were encapsulated into $\beta$-cyclodextrin microstructures and kept at $4^{\circ} \mathrm{C}$ for up to 15 days. $\beta$-cyclodextrin is an excellent transport agent due to the lack of significant effects on hosts (Del Valle, 2004). In order to study cell viability included inside $\beta$-cyclodextrin, we cultured serial decimal dilutions of three samples of these microstructures (1 g of sample diluted in $10 \mathrm{~mL}$ of phosphate buffer) at different time intervals $(0$, 7,15 , and 30 days of storage) in TSA and incubated at $37^{\circ} \mathrm{C}$ for $48 \mathrm{~h}$. Cells viability was reduced to $15-30$ days of storage (Kruskal-Wallis, $\mathrm{H}_{2,11}=9.36, P=0.025$ ). Following a conservative strategy, $\beta$-cyclodextrin complex was produced every 15 days in order to ensure cell viability. UGRA10$\beta$-cyclodextrin microstructures were mixed with the food of experimental laying hens at a final concentration of $10^{8}$ Colony Forming Units per gram (CFU/g) of fodder. Probiotic was administered daily throughout the experiment.

\section{Enumeration of Microorganisms in Fecal Samples}

Once in the lab, fecal samples were weighted, transferred to lab blender bags, and diluted 10-fold in phosphate saline buffer added with $0.5 \mathrm{~g} / \mathrm{L}$ cysteine hydrochloride (for ensuring viability of anaerobic bacteria). The samples were homogenized using a stomacher lab blender (IUL Instruments, Spain) for $2 \mathrm{~min}$. For each fecal treatment and sampling point $(7,15,40$, and 76 days), three sets of samples were collected. Each set consisted of a mixture of seven fecal samples from different cages with the same treatment.

Decimal serial dilutions of each set were performed and cultured in triplicate on Wilkins-Chalgren agar for total anaerobic bacteria (Scharlau, S.L., Spain) and Slanetz-Bartley agar for Enterococcus sp. (Scharlau, S.L., Spain). Plates were incubated at $37^{\circ} \mathrm{C}$ for $48 \mathrm{~h}$ in $2.5 \mathrm{~L}$ anaerobic chambers (Oxoid) and 2.5 L AnaeroGen Compact system (Thermo Scientific). Bacterial counts were expressed as CFU/g per gram of fecal sample.

\section{E. faecalis UGRA10 Indirect Detection in Fecal Samples}

We tested the inhibition capacity of isolates from fecal samples against two indicator strains, E. faecalis S-47 and E. faecalis UGRA10. We expected the Enterococcus population in feces of the treated group to be dominated by E. faecalis UGRA10, so most of the isolates will produce inhibition halos against S-47 (Cebrian et al., 2012). However, these halos will disappear in the presence of the original strain due to the fact that E. faecalis UGRA10 is immune to its own bacteriocin (Cebrian et al., 2012).

Indicator strains were cultured from the stock of the Lactic Acid Bacteria Laboratory in the University of Granada. After isolation in Brain Heart Infusion agar (BHA), colonies were cultured overnight in $6 \mathrm{~mL}$ BHI. The antagonistic activity was tested following Tagg and Mcgiven (1971). Stainless steel cylinders for antibiotics (diameter: $8 \mathrm{~mm}$, height: $10 \mathrm{~mm}$; Scharlab, S.L.) were placed on a layer of $10 \mathrm{~mL}$ Müller-Hilton agar (Scharlau, S.L.) buffered with phosphate buffer saline $(\mathrm{pH}$ 7.2, $M=0.2$ ). Afterward, a $6 \mathrm{~mL}$ of BHA (Scharlau, S.L.) tempered around $55^{\circ} \mathrm{C}$, were inoculated with one of the indicator strains (around $10^{8} \mathrm{CFU}$ per $\mathrm{mL}$ ), shaken in a vortex and extended over the Müller-Hilton agar. Once the BHA solidified, the cylinders were taken out, leaving a circular hole in the BHA layer.

From Slanetz-Bartley agar plates, we selected 320 colonies randomly from plates for each treatment and sampling (2 treatments $\times 4$ sampling times $\times 40$ colonies). Each colony was incubated overnight in tubes containing $6 \mathrm{~mL}$ of BHI tubes, $1 \mathrm{~mL}$ was centrifuged and $100 \mu \mathrm{L}$ of supernatant were added to the 
holes. Plates were incubated during $18-24 \mathrm{~h}$ at $37^{\circ} \mathrm{C}$. Inhibition activity was measured as presence or absence of inhibition halo.

\section{High-Throughput Sequencing}

Bacterial total DNA from ileum and caecum samples was extracted by following the Modified Salting-Out Procedure by Martín-Platero et al. (2007). Amplicon PCR was performed from bacterial total DNA on the V4 region of the 16S rRNA gene by using the primer pair 515f ( $5^{\prime}$-GTGCCAGCMGCCGCGGTAA$\left.3^{\prime}\right)$ - 786r (5'-GGACTACHVGGGTWTCTAAT-3') with Golay barcodes on the forward primer. High-throughput sequencing was performed on Illumina Miseq platform in the Scientific Instrumental Center at the University of Granada (Spain). Ileum and caecum of 5 control and 10 treated hens were used in subsequent analyses, for both sampling times (on days 40 and 76). Six samples failed to amplify (see distribution in Supplementary Table S1). Sequences are available in the Sequence Read Archive (SRA) in the GenBank - NCBI webpage ${ }^{1}$ under Accession Nos. SAMN09603288 to SAMN9603361.

Subsequent analyses were performed with QIIME2 v2018.02 (Quantitive Insights In Microbial Ecology, Caporaso et al., 2010). Primer trimming, pair joining, and quality filtering were performed by using default parameters. Afterward, we used Deblur, a sub-operational-taxonomic-unit (sOTU) approach, in order to remove sequencing errors (Amir et al., 2017). We used the fragment insertion script implemented in QIIME2, a script that performs the sequence alignment and de novo phylogenetic tree (Janssen et al., 2018). Taxonomy assignment was based on Greengenes 13_08 with a similarity of 99\% (DeSantis et al., 2006). Finally, chloroplasts and mitochondria were removed from the sOTU table, but Cyanobacteria were retained in subsequent analyses (Ley et al., 2005).

\section{Statistical Analysis}

We used general linear models (GLMs) to explore the effect of the treatment, sampling date and their interaction in different dependent variables: bacterial cultures, number of eggs (Supplementary Table S2), and different indexes of alpha diversity. We also explored the effects of egg size as factor (S, M, L, or XL as describe above). Whitaker (1972) defined diversity in three different levels: alpha diversity is the diversity found in a sample; beta diversity is the compositional difference between samples; and gamma diversity is the diversity at the regional scale. We calculated three different alpha diversity indexes from the sOTU table: bacterial operational taxonomic unit (OTU) richness (or number of observed OTUs), Faith's phylogenetic diversity index (Faith and Baker, 2006) and chao1 (Chao, 1984). Residuals of the dependent variables after analyses followed normal distribution (Kolmogorov-Smirnov normality test; $P>0.20$ ) and were homoscedastic (Levene's test for homogeneity of variances, all $P>0.19$ ). These results validate the use of parametric statistical tests. These analyses were performed in Statistica 10.0.

Beta diversity distance matrixes were calculated using Unifrac distance (Lozupone and Knight, 2005) based on a rarefied sOTU

${ }^{1}$ https://www.ncbi.nlm.nih.gov/sra/ table at 1800 sequences depth per sample. Both weighted and unweighted Unifrac distance matrixes were used in subsequent analyses as we do not have a priori predictions in the effects of the independent variables (treatment, sampling date, and gut portion) on the bacterial community. Weighted Unifrac gives more importance to the most abundant bacteria as it takes into account sequence abundance per sOTU, while unweighted Unifrac gives similar weight to all bacterial sOTU present in the samples, i.e., it gives more importance to the minority bacteria as it takes into account the presence or absence of a sOTU. Procrustes ANOVA was used to test these effects on both Unifrac distance matrixes (Collyer et al., 2015), using the geomorph (Adams and Otarola-Castillo, 2013) and vegan (Oksanen et al., 2016) packages. Principal Coordinate Analyses were performed and visualizations of the three first PCoA axes were plotted using Emperor 2018.2.0 (Vazquez-Baeza et al., 2013).

\section{RESULTS}

\section{Alpha Diversity of Bacterial Community in Ileum and Caecum}

Ileum microbiome of control hens on both 40 and 76 days were dominated at the class level by Clostridia, Bacteroidia, Erysipelotrichi, Mollicutes, Deltaproteobacteria, and Bacilli (Figure 1 and Supplementary Figure S1). These dominant classes were present in E. faecalis UGRA10 treated hens on day 40 , although proportions of each class changed, being the class Clostridia the only dominant one (Figure 1 and Supplementary Figure S1). The ileum community in the control hens was very diverse at the genus level, dominated by Desulfovibrio, Bacteroides, an unknown genus of the order Bacteroidales, an unknown genus of the family Ruminococcaceae and an unknown genus of the family Mogibacteriaceae (Supplementary Figure S2). The bacterial community of samples from hens treated with $E$. faecalis UGRA10 was very similar, although other dominant genus as Phascolarctobacterium or Megamonas appeared (Supplementary Figure S2).

Operational taxonomic unit richness in the ileum differed significantly between treatments throughout the experimental period (Table 1). While E. faecalis UGRA10 group kept similar levels of bacterial OTU richness, the control one experienced an increase in OTU richness until reaching similar levels to those of the treatment group at day 76 (Figure 2 and Supplementary Table S3). Similar pattern was marginally significant in the case of Faith's diversity index (see interaction term in Faith's diversity index in ileum, Table 1).

The bacterial community of caecum was more diverse than that of ileum (Figure 1 and Supplementary Figure S1). Major classes on days 40 and 76 in both experimental groups included Clostridia, Deltaproteobacteria, Bacteroidia and the unknown phylum OP8 (Figure 1 and Supplementary Figure S1). The genera abundance between treatments and sampling date followed similar patterns. Bacterial community was dominated by Phascolarctobacterium, Fusobacterium, Desulfovibrio, an unknown genera belonging to the class Cyanobacteria 


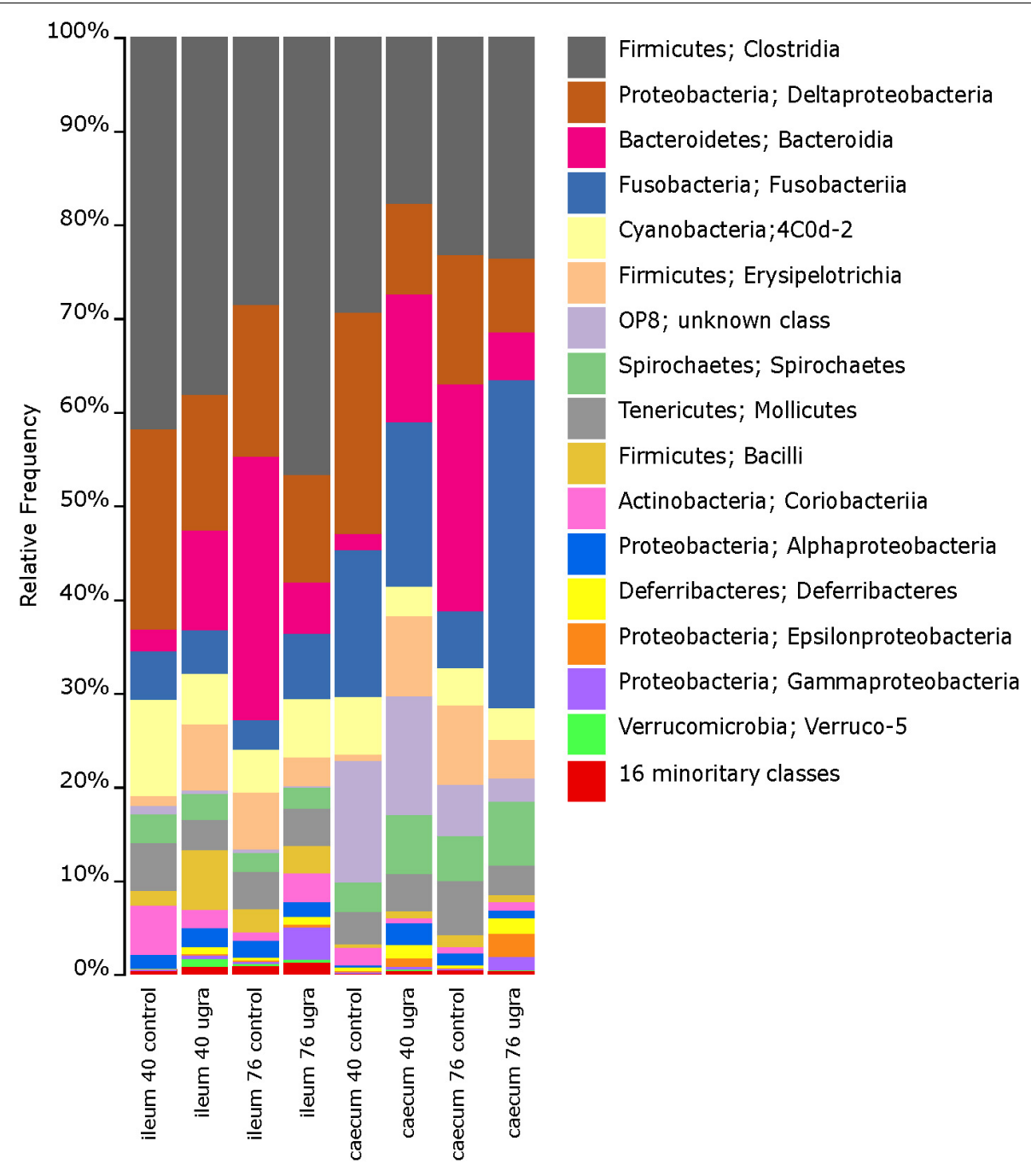

FIGURE 1 | Bar plots of average relative bacterial abundance in gut regions of laying hens at the class level, grouped by sampling time and treatment. Classes in the legend are sorted by sequence relative abundance, from most abundant to least abundant. UGRA refers to hen fed Enterococcus faecalis UGRA10 at $10^{8}$ CFU per gram of fodder per day; while 40 and 76 refers to the number of days after the experiment started.

and Megamonas (Supplementary Figures S2A,B). Alpha diversity was very similar between treatment groups, showing no significant changes throughout the experimental period (Table 1).

\section{Effects of Treatment and Sampling Date on Beta Diversity}

In the ileum region, changes of bacterial communities throughout the experiment period varied from one treatment to another (see Figure 3 and the interaction term in Table 2). Interestingly, control communities on day 76 overlapped with bacterial communities of $E$. faecalis UGRA10 treatment.

Treatment explained a significant proportion of the variance in bacterial community of caecum (both weighted and unweighted Unifrac) and its effect depends on the sampling date (see interaction term in Figure 4 and Table 2).

\section{Presence of $E$. faecalis in Feces}

Cultures from each sample were highly and significantly correlated within each triplicate (Kruskal-Wallis, bacterial count as dependent variable, sample as factor, $\mathrm{H}_{23,72}=62.44$, $P<0.001$ ), so we calculated the average values for each set of samples within each sample date and each bacterial culture.

Enterococcus sp. was successfully recovered from all SlanetzBartley agar plates [control, $N=72, \log 10$ CFUs $=6.55 \pm 0.16$ (average \pm SE); E. faecalis UGRA10: $N=72,6.67 \pm 0.20]$. However, treatment, sampling date or their interactions did not significantly explain variation in bacterial counts of Enterococcus sp. (GLM, average bacterial count, treatment as factor, $F_{1,20}=0.01, P=0.915$, sampling time as covariable, $F_{1,20}=2.15, P=0.158$, interaction, $\left.F_{1,20}=0.13, P=0.721\right)$.

Following a similar pattern, total anaerobic bacteria (control, $N=72, \log 10$ CFUs $=7.27 \pm 0.99 ;$ E. faecalis UGRA10: $N=72$, $7.40 \pm 0.86)$ did not differ between treatments, sampling date 
TABLE 1 | General linear Models exploring the effects of treatment (control and E. faecalis UGRA10 administration) and sampling time (days 40 and 76) in the different alpha diversity indexes of the bacterial community of ileum and caecum of laying hens.

\begin{tabular}{|c|c|c|c|c|}
\hline & Explanatory variables & d.f. & $\boldsymbol{F}$ & $P$ \\
\hline \multicolumn{5}{|l|}{ Ileum } \\
\hline \multirow[t]{3}{*}{ Species richness } & Treatment & 1,23 & 12.83 & 0.002 \\
\hline & Time & 1,23 & 1.79 & 0.194 \\
\hline & Treatment $\times$ Time & 1,23 & 5.18 & 0.032 \\
\hline \multirow[t]{3}{*}{ Pielou evenness } & Treatment & 1,23 & 0.27 & 0.608 \\
\hline & Time & 1,23 & 5.32 & 0.030 \\
\hline & Treatment $\times$ Time & 1,23 & 1.52 & 0.230 \\
\hline \multirow[t]{3}{*}{ Faith's diversity index } & Treatment & 1,23 & 10.70 & 0.003 \\
\hline & Time & 1,23 & 1.40 & 0.249 \\
\hline & Treatment $\times$ Time & 1,23 & 4.08 & 0.055 \\
\hline \multirow[t]{3}{*}{ Shannon's diversity index } & Treatment & 1,23 & 1.24 & 0.277 \\
\hline & Time & 1,23 & 1.60 & 0.219 \\
\hline & Treatment $\times$ Time & 1,23 & 0.01 & 0.987 \\
\hline \multicolumn{5}{|l|}{ Caecum } \\
\hline \multirow[t]{3}{*}{ Species richness } & Treatment & 1,23 & 0.23 & 0.636 \\
\hline & Time & 1,23 & 0.41 & 0.528 \\
\hline & Treatment $\times$ Time & 1,23 & 0.00 & 0.966 \\
\hline \multirow[t]{3}{*}{ Pielou evenness } & Treatment & 1,23 & 0.23 & 0.638 \\
\hline & Time & 1,23 & 0.84 & 0.370 \\
\hline & Treatment $\times$ Time & 1,23 & 0.41 & 0.529 \\
\hline \multirow[t]{3}{*}{ Faith's diversity index } & Treatment & 1,23 & 0.72 & 0.405 \\
\hline & Time & 1,23 & 1.21 & 0.283 \\
\hline & Treatment $\times$ Time & 1,23 & 0.35 & 0.561 \\
\hline \multirow[t]{3}{*}{ Shannon's diversity index } & Treatment & 1,23 & 0.26 & 0.618 \\
\hline & Time & 1,23 & 0.29 & 0.597 \\
\hline & Treatment $\times$ Time & 1,23 & 0.21 & 0.650 \\
\hline
\end{tabular}

D.f. refers to degree of freedom. Significant $P$-values are shown in bold.

or their interaction (GLM, average bacterial count, treatment as factor, $F_{1,20}=0.05, P=0.827$, sampling time as covariable, $F_{1,20}=0.58, P=0.454$, interaction, $\left.F_{1,20}<0.01, P=0.990\right)$.

\section{E. faecalis UGRA10 Indirect Detection in Feces}

The percentage of colonies that showed inhibition properties against E. faecalis S-47 increased along the experiment but only in the treatment group. In the control group, a low percentage of colonies showed antagonism against S-47 (Table 3). Interestingly, most of the colonies that produced antagonism against $E$. faecalis S-47 in the treatment group did not show inhibition against E. faecalis UGRA10, except 1 out of 30 colonies on day 80 . Most of these colonies may be attributed to E. faecalis UGRA10, as this strain is immune against its own bacteriocin (Table 3 ).

\section{Egg Production}

As 13 hens were slaughtered on day 40, we analyzed both periods separately, before and after slaughtering. Egg production was maintained in the first half of the experiment, regardless of the treatment (Figure 5A and Table 4), as both slopes of egg production did not differ from 0 (control slope $=-0.007$,

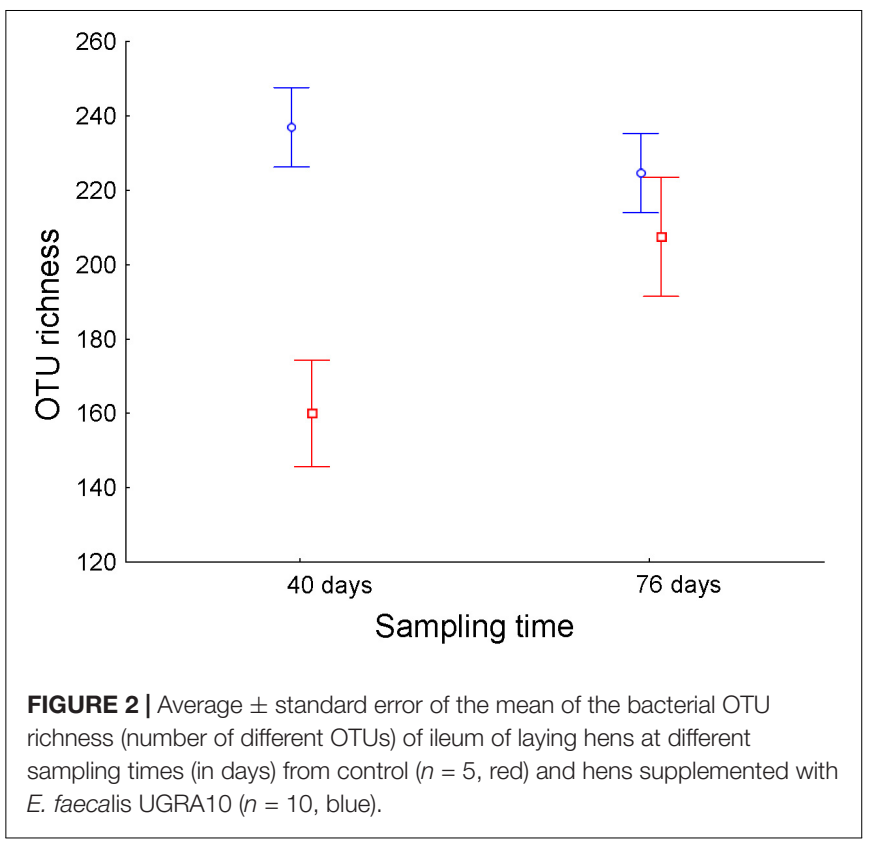

$r=-0.02, P>0.915$; experimental slope $=-0.09 ; r=-0.24$; $P=0.277$ ). However, egg production along the second period significantly differed between treatments. While egg production of control hens significantly decreased (slope $=-0.15, r=-0.51$, $P=0.020)$, hens supplemented with $E$. faecalis UGRA10 maintained egg production along this period (slope $=0.07$, $r=0.24, P=0.293$; Figure 5B and Table 4).

Laying hens throughout the experiment period produced significantly more eggs of size L (between 63 and $73 \mathrm{~g}$ ), regardless of the treatment (GLM, number of eggs as dependent variable, Treatment as factor, $F_{1,47}=0.04, P=0.848$, Egg size as factor, $F_{2,47}=370.69, P<0.001$, Sampling date as covariable, $F_{1,47}=15.03, P<0.001$, Interaction between egg size and treatment, $F_{2,47}=0.07, P=0.931$; Figure 6). Interestingly, no hen produced any egg of size $S$ (less than $53 \mathrm{~g}$ ).

\section{DISCUSSION}

The addition of $E$. faecalis UGRA10 in the diet of laying hens had a positive and significant effect on egg production during the second half of the experiment, allowing these hens to maintain production levels throughout their productive lives. These beneficial productive changes were accompanied by significant changes in the gut microbiota and an increase in the presence of E. faecalis UGRA10 along the experimental period in the feces. These results support the use of E. faecalis UGRA10 as an enhancer of egg production in laying hens, while modifying bacterial community diversity.

Maintenance of egg production levels throughout laying hens' welfare is essential in poultry and the use of probiotics is one of the most promising strategies to achieve this goal (Patterson and Burkholder, 2003; Kabir, 2009). Our results support this strategy as treated hens maintained egg production, 


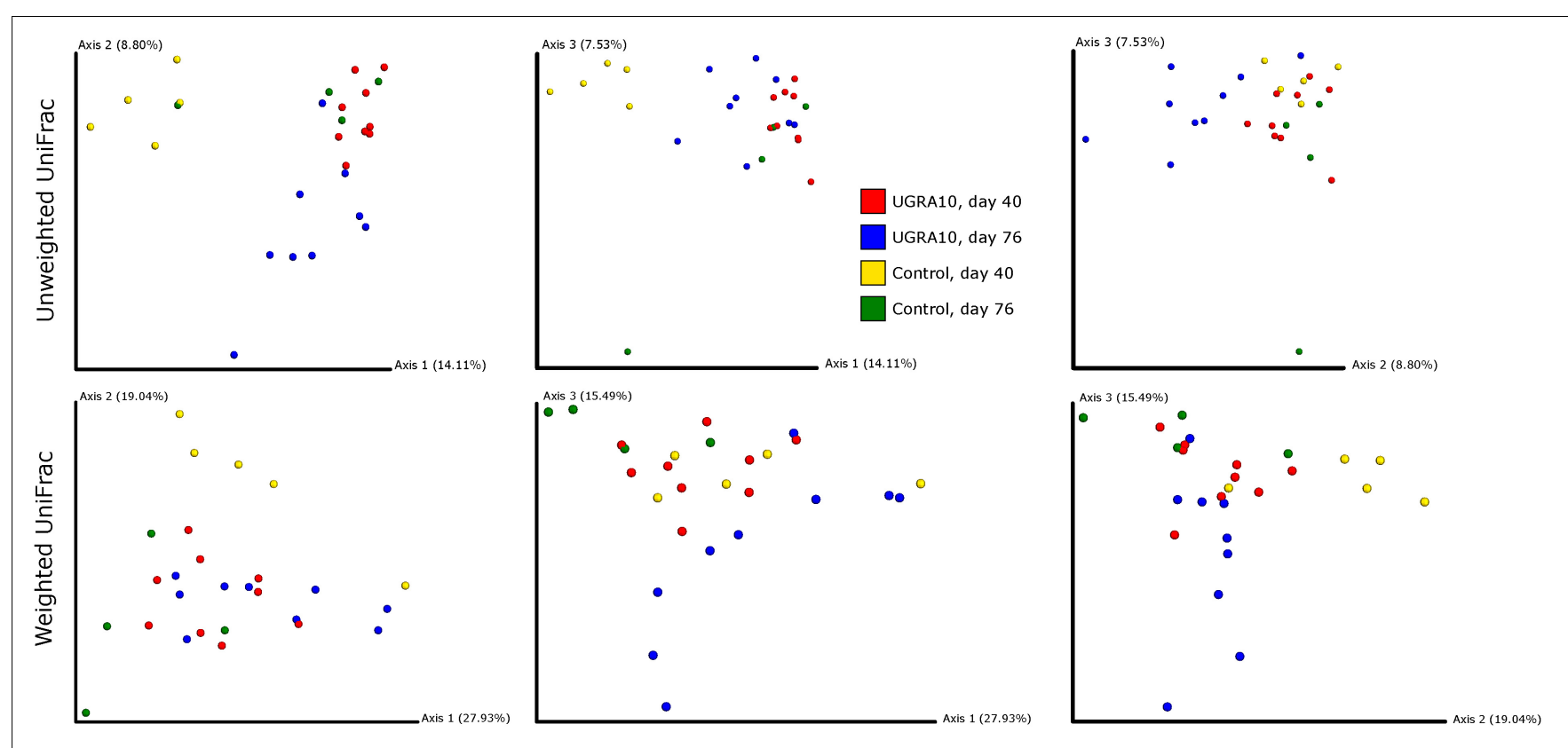

FIGURE 3 | Two-dimensional figures showing three first axes of Principal Coordinate Analysis and representing bacterial communities of ileum of laying hens, using Unweighted and Weighted Unifrac distance matrixes. Proportion of explained variance by each PCo axes is also shown.

especially during the second half of the experimental period, without altering egg size. In fact, large size eggs (L: 63-73 g; and XL: $>73 \mathrm{~g}$ ) were the most produced eggs. These results are really promising as large size eggs are most demanded in different markets (Araneda Uson, 2006; Souza, 2008; Bejaei, 2009; Reichmann Bellino and Arias Nieto, 2016; Zakowska-Biemans and Tekien, 2017). Different bacterial strains have been studied and their effects tested on animal performance, egg production, enhancement of immune system and changes in gut microbiome. For instance, Rhodobacter capsulatus improved hen health and egg quality during the last period of the laying (Lokhande

TABLE 2 | PROCRUTES ANOVA exploring the effects of treatment, sampling date and their interaction in the bacterial community of laying hens fed with a control diet or supplemented with Enterococcus faecalis UGRA10.

\begin{tabular}{|c|c|c|c|c|c|}
\hline & $\begin{array}{l}\beta \text {-Diversity distance } \\
\text { matrix }\end{array}$ & $\begin{array}{l}\text { Explanatory } \\
\text { variables }\end{array}$ & d.f. & $\boldsymbol{F}$ & $P$ \\
\hline \multirow[t]{6}{*}{ lleum } & Unweighted Unifrac & Day & 1,23 & 1.47 & 0.020 \\
\hline & & Treatment & 1,23 & 2.48 & 0.001 \\
\hline & & Day $\times$ Treatment & 1,23 & 2.57 & 0.001 \\
\hline & Weighted Unifrac & Day & 1,23 & 1.63 & 0.060 \\
\hline & & Treatment & 1,23 & 2.04 & 0.026 \\
\hline & & Day $\times$ Treatment & 1,23 & 4.16 & 0.001 \\
\hline \multirow[t]{6}{*}{ Caecum } & Unweighted Unifrac & Day & 1,23 & 1.44 & 0.029 \\
\hline & & Treatment & 1,23 & 2.12 & 0.004 \\
\hline & & Day $\times$ Treatment & 1,23 & 2.06 & 0.003 \\
\hline & Weighted Unifrac & Day & 1,23 & 1.54 & 0.105 \\
\hline & & Treatment & 1,23 & 2.32 & 0.024 \\
\hline & & Day $\times$ Treatment & 1,23 & 2.60 & 0.006 \\
\hline
\end{tabular}

D.f. refers to degree of freedom. Significant P-values are shown in bold. et al., 2013); Bacillus subtilis has been tested successfully against Salmonella infection (Oh et al., 2017) and increased egg quality and production (Ribeiro et al., 2014); or B. licheniformis acted as an immune system enhancer and a hormone regulator (Wang et al., 2017). The use of E. faecalis UGRA10 showed some advantages as enterococci are common bacteria in warmblood animals (Krieg and Holt, 1984) and have a beneficial interaction with immune system (Franz et al., 2011), hormones and metabolism (Zhao et al., 2013) and gut microbiota (Han et al., 2013; Park et al., 2016). We recovered a high proportion of Enterococcus sp. in all fecal samples, around one logarithmic unit smaller than total anaerobic bacteria, so this taxon is wellrepresented in those fecal samples. Interestingly, the presence of E. faecalis UGRA10 increased during the experimental period in the treated group, until it became dominant in fecal samples. This result suggests that this strain may substitute other Enterococcus strains/species. This substitution between Enterococcus species has been reported before (Sakai et al., 2006; Saelim et al., 2012) and may be caused by the production of antagonistic substances against closely related species (Foulquie Moreno et al., 2003, 2006; Martín-Platero et al., 2006, 2009; RuizRodríguez et al., 2013). In this sense, the ability of allochthonous bacteria, such as probiotics, to establish and flourish in complex bacterial ecosystems (as the intestine of vertebrates) is low and depends on taxon (Thomas and Versalovic, 2010). However, the positive effects of these transient bacteria are related to the active and temporary interaction with the host immune system (Are et al., 2008; Thomas and Versalovic, 2010), even though they do not establish as resident members of the bacterial community (Derrien and Vlieg, 2015). For instance, Enterococcus as probiotic in poultry seems to induce physical changes in the gut structure, especially in the development of villus height/crypt 


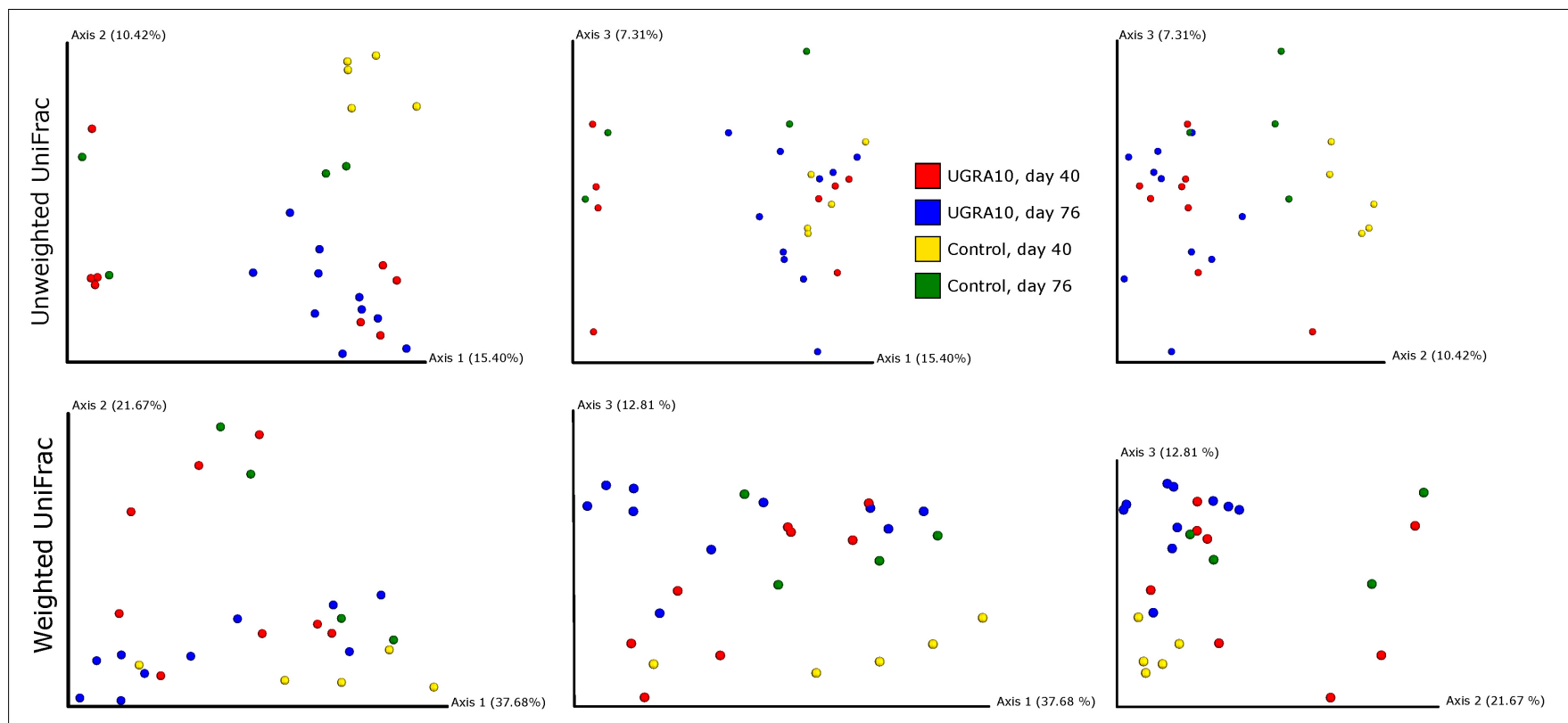

FIGURE 4 | Two-dimensional figures showing three first axes of Principal Coordinate Analysis representing bacterial communities of caecum of laying hens, using Unweighted and Weighted Unifrac distance matrixes. Proportion of explained variance by each PCo axes is also shown.

depth ratio and villus height in the ileum (Awad et al., 2008), hence the increase in nutrient digestibility (Park et al., 2016). An alternative and non-exclusive hypothesis would point out the role of enterococci as immune system stimulators (Franz et al., 2011) or hormone mediators in avian performance (Zhao et al., 2013). These interactions with the immune system have been examined in model organisms (Foligne et al., 2007; de Vrese and Schrezenmeir, 2008), although our knowledge of this interaction in poultry is still scarce. In broilers, probiotic supplementation in the diet increases serum/plasma immunoglobulin levelsandfoster change in immune cell numbers and their phagocytosis capacities (Apata, 2008; Lee et al., 2011; Zhang et al., 2012; Salim et al., 2013; Ahmed et al., 2014; Beirao et al., 2018). The use of E. faecium as a probiotic produces increases in antibody titers against pathogens are also found (Nayebpor et al., 2007), changes

TABLE 3 | Percentages of colonies from fecal samples of laying hens that showed inhibition against indicators strain $E$. faecalis S-47 and percentage of those colonies that inhibition halo disappear against $E$. faecalis UGRA10.

\begin{tabular}{llcc}
\hline $\begin{array}{l}\text { Sampling } \\
\text { time }\end{array}$ & Treatment & $\begin{array}{c}\text { \% inhibitor } \\
\text { colonies } \\
\text { against S-47 }\end{array}$ & $\begin{array}{c}\text { \% of colonies where } \\
\text { inhibition halo disappeared } \\
\text { against UGRA10 }\end{array}$ \\
\hline 7 & Control & 0.0 & 0.0 \\
\multirow{3}{*}{15} & UGRA10 & 0.0 & 0.0 \\
& Control & 2.5 & 0.0 \\
38 & UGRA10 & 10.0 & 100.0 \\
& Control & 0.0 & 0.0 \\
80 & UGRA10 & 37.5 & 100.0 \\
& Control & 2.5 & 0.0 \\
& UGRA10 & 75.0 & 96.7
\end{tabular}

inliver metabolic efficiency (Zheng et al., 2016), modifications in intestinal mucosa proteome (Luo et al., 2013) or increases in leptin levels and hence growth rate (Arslan et al., 2004). In laying hens, a combination of probiotics enhanced antibody response (Zhang et al., 2012). However, the mechanisms that explain the interaction between the use of Enterococcus as probiotic and the immune system and/or hormones in laying hens are still elusive, so further experiments are necessary to elucidate these relationships.

Microbiome of ileum in broilers is dominated by Lactobacillus, followed by Clostridium, Streptococcus, and Enterococcus species (Lu et al., 2003). However, Clostridium sp. and closely related species became dominant in caecum of laying hens, followed by members of phylum Bacteroidetes, especially Bacteroides, Butyricimonas, and Prevotella (Callaway et al., 2009; Nordentoft et al., 2011). Our results are consistent with these previous findings, especially at the phylum level, although differ in the importance of different genera. These differences in bacterial community were found mainly in ileum between treatment and sampling time. Treated hens harbored more bacterial species and a wider range of phylogenetic diversity in the ileum than control ones. Nevertheless, bacterial community in caecum showed similar levels of alpha diversity between treatments. These results of alpha diversity are supported with results of beta diversity. Bacterial communities grouped closely when we compared similarities in Unifrac distance matrixes, showing microbiome change in the gut of treated hens.

The beneficial effects of antibiotics on broilers and hens are related to changes in the microbial community of the gut (Choi et al., 2018) especially toward short-chain fatty acid producers (Banerjee et al., 2018), but also to the increase of amino acid metabolites, fatty acids, nucleosides, and 


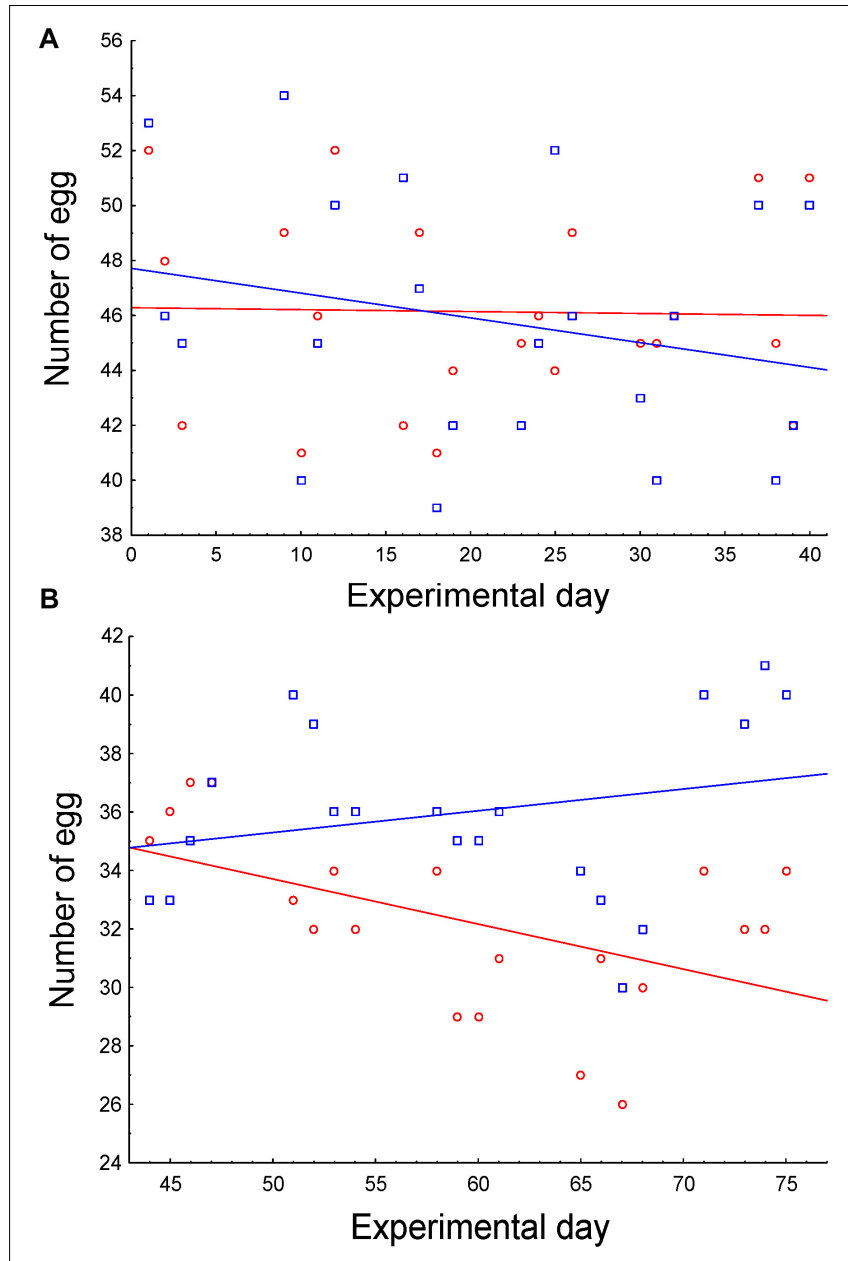

FIGURE 5 | Correlations between number of eggs and sampling date as function of treatment, during the first $\mathbf{( A )}$ and second $\mathbf{( B )}$ half of the experimental period. Control hens (red) were fed a basal diet while experimental hens (blue) were supplemented with E. faecalis UGRA10.

vitamins (Gadde et al., 2018). Alternatively, antibiotics improve performance through an anti-inflammatory effect mediated by the intestinal epithelium (Niewold, 2007). In spite of the differences in nature of antibiotics and probiotics, the effects of both agents on animals seem to be similar. Enterococcus used as a probiotic in poultry induces shifts of fecal microbiota (Han et al., 2013), especially reducing Salmonella populations (Waters et al., 2005), although the major phyla abundance (Bacteroidetes and Firmicutes) remains stable (Zhao et al., 2013). The diet supplemented with E. faecalis UGRA10 produced changes in the bacterial community, both in the ileum and the caecum, and supports, at least partially, the hypothesis that the beneficial effect on the maintenance of egg production could be mediated by effects on the gut microbiome. Further experiments should be conceived in order to unveil possible mechanisms in relation to the stimulation of the immune system or the interaction with hormones.

This experiment supports the use of E. faecalis UGRA10 in the diet of laying hens for successfully maintaining egg production
TABLE 4 | General Linear Models explaining egg production per laying hen in both control and diet supplemented with Enterococcus faecalis UGRA10, during both halves of the experimental period.

\begin{tabular}{llccc}
\hline & Explanatory variables & d.f. & $\boldsymbol{F}$ & $\boldsymbol{P}$ \\
\hline First half & Treatment & 1,40 & 0.65 & 0.425 \\
& Sampling date & 1,40 & 0.88 & 0.353 \\
& Treatment $\times$ Sampling date & 1,40 & 0.65 & 0.425 \\
Second half & Treatment & 1,36 & 6.22 & $\mathbf{0 . 0 1 7}$ \\
& Sampling date & 1,36 & 0.76 & 0.390 \\
& Treatment $\times$ Sampling date & 1,36 & 6.22 & $\mathbf{0 . 0 1 7}$ \\
\hline
\end{tabular}

D.f. refers to degree of freedom. Significant results are in bold.

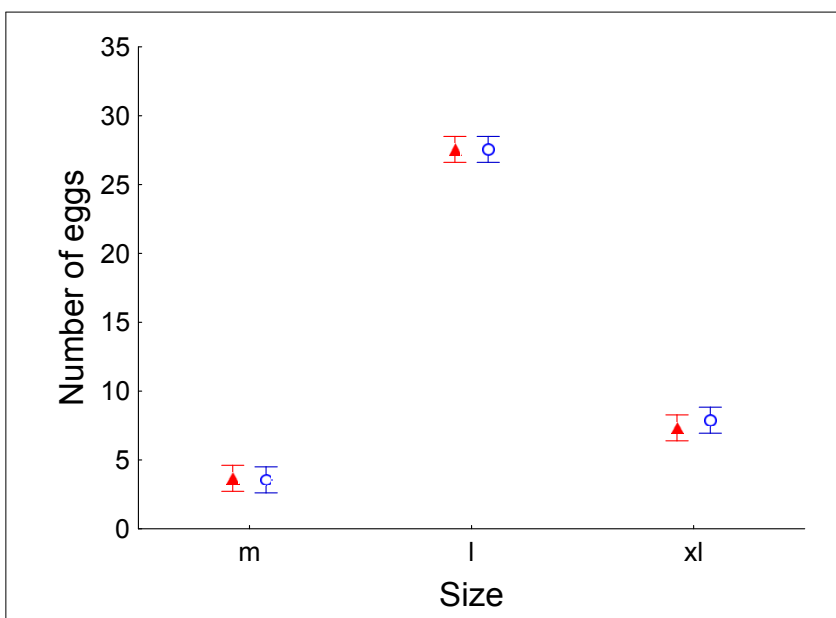

FIGURE 6 | Average \pm Standard error of the mean number of eggs produced by laying hens. Once per week, number of eggs was recorded as well as their weight and their size (m: medium; I: large; xl: extra-large). Control values are shown in red while values of laying hens supplemented with $E$. faecalis UGRA10 in the diet are shown in blue.

levels and change microbiome diversity, similar effects to those found with the use of antibiotics (Park et al., 2016). However, the use of a bacterial strain would avoid the use of antibiotics in poultry, since a new member of the bacterial community is introduced instead of high antibiotic doses during porlongated exposition times.

\section{ETHICS STATEMENT}

This study was carried out in accordance with the national regulations and the European directive for the protection of animal welfare in research (Directive 2010/63/EU, European Commission, 2010). This study was performed in a regular poultry farm, following Spanish (Law 32/2007, Real Decreto 348/2000, Real Decreto 3/2002, Real Decreto 372/2003) and European regulation for poultry exploitations (Directive 98/58/CE, European Commission, 1998). We also followed the recommendations provided by the National Ministry of Agriculture, Food and Environment (Ministerio de Agricultura, Alimentación, y Medio Ambiente, Guideless of good practices of animal management and welfare in egg producing farms, 2012). 


\section{AUTHOR CONTRIBUTIONS}

JP-S, AM-P, JA-R, AB, and MM-B conceived and planned the experiments. JA-R and $A B$ carried out the farm experiments. JA-R, MR-R, and MZ-G contributed to sample preparation and performed lab analyses. JP-S, AM-P, JA-R, MR-R, MZ-G, SR-R, $\mathrm{MM}, \mathrm{EV}$, and MM-B contributed to the interpretation of the results. JP-S and AM-P took the lead in writing the manuscript. All authors provided critical feedback and helped shape the research, analysis, and manuscript.

\section{FUNDING}

This research was funded by the Spanish Ministry of Science and Innovation, Consejería de Economía, Innovación, Ciencia y Empleo (Junta de Andalucía), the University of GranadaCEI BioTic (Project No. P-BS-37), and the INTERCONECTA program (Spanish Ministry of Economy and Competitiveness). JP-S was funded by Junta de Andalucia (Proyectos de Excelencia 2011- RNM-8147).

\section{ACKNOWLEDGMENTS}

We would like to show our gratitude to the three reviewers for their useful suggestions, which undoubtedly have improved the quality of the present manuscript.

\section{REFERENCES}

Adams, D. C., and Otarola-Castillo, E. (2013). geomorph: an r package for the collection and analysis of geometric morphometric shape data. Methods Ecol. Evol. 4, 393-399. doi: 10.1111/2041-210x.12035

Ahmed, S. T., Islam, M. M., Mun, H.-S., Sim, H.-J., Kim, Y.-J., and Yang, C.J. (2014). Effects of Bacillus amyloliquefaciens as a probiotic strain on growth performance, cecal microflora, and fecal noxious gas emissions of broiler chickens. Poultry Sci. 93, 1963-1971. doi: 10.3382/ps.2013-03718

Alfredson, D. A., and Korolik, V. (2007). Antibiotic resistance and resistance mechanisms in Campylobacter jejuni and Campylobacter coli. FEMS Microbiol. Lett. 277, 123-132.

Amir, A., Mcdonald, D., Navas-Molina, J. A., Kopylova, E., Morton, J. T., Xu, Z. Z., et al. (2017). Deblur rapidly resolves single-nucleotide community sequence patterns. Msystems 2, e00191-16. doi: 10.1128/mSystems.00191-16

Ananou, S., Munoz, A., Galvez, A., Martinez-Bueno, M., Maqueda, L., and Valdivia, E. (2008). Optimization of enterocin AS-48 production on a whey-based substrate. Int. Dairy J. 18, 923-927. doi: 10.1016/j.idairyj.2008.02.001

Apata, D. F. (2008). Growth performance, nutrient digestibility and immune response of broiler chicks fed diets supplemented with a culture of Lactobacillus bulgaricus. J. Sci. Food Agr. 88, 1253-1258. doi: 10.1002/jsfa.3214

Araneda Uson, R. P. (2006). Percepción de calidad de huevo vista por un grupo de consumidores del Gran Santiago. Bachelor thesis. Santiago de Chile (Chile): Universidad de Chile, Chile.

Are, A., Aronsson, L., Wang, S., Greicius, G., Lee, Y. K., Gustafsson, J. A., et al. (2008). Enterococcus faecalis from newborn babies regulate endogenous PPAR $_{\gamma}$ activity and IL-10 levels in colonic epithelial cells. Proc. Natl. Acad. Sci. USA 105, 1943-1948. doi: 10.1073/pnas.0711734105

Arslan, M., Ozcan, M., Matur, E., Cotelioglu, U., and Ergul, E. (2004). The effects of probiotic on leptin level, body, liver and abdominal fat weights during the rapid growth phase of broilers. Indian Vet. J. 81, 416-420.

\section{SUPPLEMENTARY MATERIAL}

The Supplementary Material for this article can be found online at: https://www.frontiersin.org/articles/10.3389/fmicb. 2019.01042/full\#supplementary-material

FIGURE S1 | Bar plots of bacterial relative abundance at the class level in laying hens at different gut region, sampling times, and treatments. Classes in the legend are sorted by sequence relative abundance, from most abundant to lowest abundant. UGRA refers to hen fed with Enterococcus faecalis UGRA10 at $10^{8}$ Colony Forming Units per grams of fodder; while 40 and 80 refers to the number of days after the experiment started.

FIGURE S2 | Bar plots of relative bacterial abundance at the genus level of ileum and caecum in laying hens at different gut region (ileum and caecum), sampling times (30 and 80 days) and treatments (control and UGRA) (A) or grouped by gut region, sampling time and treatment (B). Classes in the legend are sorted by sequence relative abundance. UGRA refers to hen fed with Enterococcus faecalis UGRA10 at $10^{8}$ Colony Forming Units per grams of fodder; while 40 and 80 refers to the number of days after the experiment started.

TABLE S1 | Sample sizes of bacterial community of ileum and caecum of laying hens, successfully amplified in Illumina MiSeq platform, at different sampling times. In parentheses, sample size before amplification.

TABLE S2 | Number of eggs produced by hens fed with control diets and supplemented with Enterococcus faecalis UGRA10 along the experimental period.

TABLE S3 | Summary of average ( \pm SE) of alpha diversity indexes based in bacterial community of ileum and caecum in laying hens sequenced by Illumina Miseq. Different indexes have been separated by gut region, sampling date and treatment. In treated group, laying hens were supplemented with Enterococcus faecalis UGRA10. Sample size is also shown.

Awad, W., Ghareeb, K., and Boehm, J. (2008). Intestinal structure and function of broiler chickens on diets supplemented with a synbiotic containing Enterococcus faecium and oligosaccharides. Int. J. Mol. Sci. 9, 2205-2216. doi: 10.3390/ijms9112205

Banerjee, S., Sar, A., Misra, A., Pal, S., Chakraborty, A., and Dam, B. (2018). Increased productivity in poultry birds by sub-lethal dose of antibiotics is arbitrated by selective enrichment of gut microbiota, particularly shortchain fatty acid producers. Microbiology 164, 142-153. doi: 10.1099/mic.0. 000597

Baños, A. (2016). Aplicación de la Tecnología de las Barreras en el Desarrollo de AS-48 Como Bioconservante Alimentario. Estudio de Probiosis de una Cepa Productora de AS-48. Ph.D. dissertation. Granada: University of Granada.

Beirão, B. C. B., Ingberman, M., Fávaro, C Jr., Mesa, D., Bittencourt, L. C., Fascina, V. B., et al. (2018). Effect of an Enterococcus faecium probiotic on specific IgA following live Salmonella enteritidis vaccination of layer chickens. Avian. Pathol. 47, 325-333. doi: 10.1080/03079457.2018.1450487

Bejaei, M. (2009). Attitudes and Preferences of Consumers/Purchasers Toward Different Types of Table Eggs. Master thesis. Vancouver: University of British Columbia.

Bode, C., Diedrich, B., Muenster, S., Hentschel, V., Weisheit, C., Rommelsheim, K., et al. (2014). Antibiotics regulate the immune response in both presence and absence of lipopolysaccharide through modulation of Toll-like receptors, cytokine production and phagocytosis in vitro. Int. Immunopharmacol. 18, 27-34. doi: 10.1016/j.intimp.2013.10.025

Callaway, T. R., Dowd, S. E., Wolcott, R. D., Sun, Y., Mcreynolds, J. L., Edrington, T. S., et al. (2009). Evaluation of the bacterial diversity in cecal contents of laying hens fed various molting diets by using bacterial tag-encoded FLX amplicon pyrosequencing. Poultry Sci. 88, 298-302. doi: 10.3382/ps.2008-00222

Capita, R., and Alonso-Calleja, C. (2013). Antibiotic-resistant bacteria: a challenge for the food industry. Crit. Rev. Food. Sci. Nutr. 53, 11-48. doi: 10.1080/ 10408398.2010.519837 
Caporaso, J. G., Kuczynski, J., Stombaugh, J., Bittinger, K., Bushman, F. D., Costello, E. K., et al. (2010). QIIME allows analysis of high-throughput community sequencing data. Nat. Methods 7, 335-336.

Carramiñana, J. J., Rota, C., Agustin, I., and Herrera, A. (2004). High prevalence of multiple resistance to antibiotics in Salmonella serovars isolated from a poultry slaughterhouse in Spain. Vet. Microbiol. 104, 133-139. doi: 10.1016/j.vetmic. 2004.08.010

Cebrian, R., Banos, A., Valdivia, E., Perez-Pulido, R., Martínez-Bueno, M., and Maqueda, M. (2012). Characterization of functional, safety, and probiotic properties of Enterococcus faecalis UGRA10, a new AS-48-producer strain. Food Microbiol. 30, 59-67. doi: 10.1016/j.fm.2011.12.002

Chao, A. (1984). Nonparametric-estimation of the number of classes in a population. Scand. J. Stat. 11, 265-270.

Choi, J. H., Lee, K., Kim, D. W., Kil, D. Y., Kim, G. B., and Cha, C. J. (2018). Influence of dietary avilamycin on ileal and cecal microbiota in broiler chickens. Poultry Sci. 97, 970-979. doi: 10.3382/ps/pex360

Clemente, J. C., Ursell, L. K., Parfrey, L. W., and Knight, R. (2012). The impact of the gut microbiota on human health: an integrative view. Cell 148, 1258-1270. doi: 10.1016/j.cell.2012.01.035

Collyer, M. L., Sekora, D. J., and Adams, D. C. (2015). A method for analysis of phenotypic change for phenotypes described by high-dimensional data. Heredity 115, 357-365. doi: 10.1038/hdy.2014.75

de Oliveira, S. D., Flores, F. S., Dos Santos, L. R., and Brandelli, A. (2005). Antimicrobial resistance in Salmonella enteritidis strains isolated from broiler carcasses, food, human and poultry-related samples. Int. J. Food Microbiol. 97, 297-305. doi: 10.1016/j.ijfoodmicro.2004.04.022

de Vrese, M., and Schrezenmeir, J. (2008). Probiotics, prebiotics, and synbiotics. Adv. Biochem. Eng. Biotechnol. 2008, 1-66.

Del Valle, E. M. M. (2004). Cyclodextrins and their uses: a review. Process Biochem. 39, 1033-1046. doi: 10.1016/s0032-9592(03)00258-9

Derrien, M., and Vlieg, J. E. V. H. (2015). Fate, activity, and impact of ingested bacteria within the human gut microbiota. Trends Microbiol. 23, 354-366. doi: 10.1016/j.tim.2015.03.002

DeSantis, T. Z., Hugenholtz, P., Larsen, N., Rojas, M., Brodie, E. L., Keller, K., et al. (2006). Greengenes, a chimera-checked 16S rRNA gene database and workbench compatible with ARB. Appl. Environ. Microb. 72, 5069-5072. doi: 10.1128/aem.03006-05

Diarra, M. S., Silversides, F. G., Diarrassouba, F., Pritchard, J., Masson, L., Brousseau, R., et al. (2007). Impact of feed supplementation with antimicrobial agents on growth performance of broiler chickens, Clostridium perfringens and Enterococcus counts, and antibiotic resistance phenotypes and distribution of antimicrobial resistance determinants in Escherichia coli isolates. Appl. Environ. Microb. 73, 6566-6576. doi: 10.1128/aem.01086-07

Diarrassouba, F., Diarra, M. S., Bach, S., Delaquis, P., Pritcrard, J., Topp, E., et al. (2007). Antibiotic resistance and virulence genes in commensal Escherichia coli and Salmonella isolates from commercial broiler chicken farmst. J. Food Protect. 70, 1316-1327. doi: 10.4315/0362-028x-70.6.1316

Dibner, J. J., and Richards, J. D. (2005). Antibiotic growth promoters in agriculture: history and mode of action. Poultry Sci. 84, 634-643. doi: 10.1093/ps/ 84.4.634

European Commission (1998). Commission Regulation (EC) No 98/1998 of 20 July 1998 Concerning the Protection of Animals Kept for Farming Purposes. Brussels: Official Journal of European Union.

European Commission (2003). Commision Regulation (EC) No 1831/2003 of the European Parliament and of the Council of 22 September 2003 on Additives for Use in Animal Nutrition. Brussels: Official Journal of European Union.

European Commission (2005). Regulation (EC) No 183/2005 of the European Parliament and of the Council of 12 January 2005 Laying Down Requirements for Feed Hygiene (Text with EEA relevance). Brussels: Official Journal of European Union.

European Commission (2008). Commission Regulation (EC) No 589/2008 of 23 June 2008 Laying Down Detailed Rules for Implementing Council Regulation (EC) No 1234/2007 as Regards Marketing Standards for Eggs. Brussels: Official Journal of European Union.

European Commission (2010). Directive 2010/63/EU of the European Parliament and of the Council of 22 September 2010 on the Protection of Animals Used for Scientific Purposes. Brussels: Official Journal of European Union.

Faith, D. P., and Baker, A. M. (2006). Phylogenetic diversity (PD) and biodiversity conservation: some bioinformatics challenges. Evol. Bioinform. 2, 121-128.
Fenimore, A., Martin, L., and Lappin, M. R. (2017). Evaluation of metronidazole with and without Enterococcus faecium SF68 in shelter dogs with diarrhea. Top. Companion Anim. Med. 32, 100-103. doi: 10.1053/j.tcam.2017.11.001

Ferket, P. R. (2004). "Alternatives to antibiotics in poultry production: responses, practical experience and recommendations," in Nutritional Biotechnology in the Feed and Food Industries, eds T. P. Lyons and K. A. Jacques (Nottinghan: Nottinghan University Press), 57-67.

Ferri, M., Ranucci, E., Romagnoli, P., and Giaccone, V. (2017). Antimicrobial resistance: a global emerging threat to public health systems. Crit. Rev. Food Sci. Nutr. 57, 2857-2876. doi: 10.1080/10408398.2015.1077192

Foligne, B., Zoumpopoulou, G., Dewulf, J., Ben Younes, A., Chareyre, F., Sirard, J.-C., et al. (2007). A key role of dendritic cells in probiotic functionality. PLoS One 2:e313. doi: 10.1371/journal.pone.0000313

Foulquie Moreno, M. R., Callewaert, R., Devreese, B., Van Beeumen, J., and De Vuyst, L. (2003). Isolation and biochemical characterisation of enterocins produced by enterococci from different sources. J. Appl. Microbiol. 94, 214-229. doi: $10.1046 /$ j.1365-2672.2003.01823.x

Foulquie-Moreno, M. R., Sarantinopoulos, P., Tsakalidou, E., and De Vuyst, L. (2006). The role and application of enterococci in food and health. Int. J. Food Microbiol. 106, 1-24. doi: 10.1016/j.ijfoodmicro.2005.06.026

Franz, C. M., Huch, M., Abriouel, H., Holzapfel, W., and Galvez, A. (2011). Enterococci as probiotics and their implications in food safety. Int. J. Food Microbiol. 151, 125-140. doi: 10.1016/j.ijfoodmicro.2011.08.014

Franz, C. M., Stiles, M. E., Schleifer, K. H., and Holzapfel, W. H. (2003). Enterococci in foods - a conundrum for food safety. Int. J. Food Microbiol. 88, 105-122. doi: 10.1016/s0168-1605(03)00174-0

Fuller, R. (1989). Probiotics in man and animals. J. Appl. Bacteriol. 66, 365-378. doi: 10.1111/j.1365-2672.1989.tb05105.x

Gadde, U. D., Oh, S., Lillehoj, H. S., and Lillehoj, E. P. (2018). Antibiotic growth promoters virginiamycin and bacitracin methylene disalicylate alter the chicken intestinal metabolome. Sci. Rep. 8:3592. doi: 10.1038/s41598-018-22004-6

Gaggia, F., Mattarelli, P., and Biavati, B. (2010). Probiotics and prebiotics in animal feeding for safe food production. Int. J. Food Microbiol. 141, S15-S28. doi: 10.1016/j.ijfoodmicro.2010.02.031

Gilchrist, M. J., Greko, C., Wallinga, D. B., Beran, G. W., Riley, D. G., and Thorne, P. S. (2007). The potential role of concentrated animal feeding operations in infectious disease epidemics and antibiotic resistance. Environ. Health Persp. 115, 313-316. doi: 10.1289/ehp. 8837

Griggs, J. P., and Jacob, J. P. (2005). Alternatives to antibiotics for organic poultry production. J. Appl. Poultry Res. 14, 750-756. doi: 10.1093/japr/14.4.750

Gustafson, R. H., and Bowen, R. E. (1997). Antibiotic use in animal agriculture. J. Appl. Microbiol. 83, 531-541. doi: 10.1046/j.1365-2672.1997.00280.x

Gyles, C. L. (2008). Antimicrobial resistance in selected bacteria from poultry. Anim. Health Res. Rev. 9, 149-158. doi: 10.1017/S1466252308001552

Habermann, W., Zimmermann, K., Skarabis, H., Kunze, R., and Rusch, V. (2001). Influence of a bacterial immunostimulant (human Enterococcus faecalis bacteria) on the recurrence of relapses in patients with chronic bronchitis. Arzneimittel-Forsch. 51, 931-937.

Han, W., Zhang, X. L., Wang, D. W., Li, L. Y., Liu, G. L., Li, A. K., et al. (2013). Effects of microencapsulated Enterococcus faecalis CG1.0007 on growth performance, antioxidation activity, and intestinal microbiota in broiler chickens. J. Anim. Sci. 91, 4374-4382. doi: 10.2527/jas.2012-5956

Hecker, M. T., Aron, D. C., Patel, N. P., Lehmann, M. K., and Donskey, C. J. (2003). Unnecessary use of antimicrobials in hospitalized patients - current patterns of misuse with an emphasis on the antianaerobic spectrum of activity. Arch. Iintern. Med. 163, 972-978.

Huttenhower, C., Gevers, D., Knight, R., Abubucker, S., Badger, J. H., Chinwalla, A. T., et al. (2012). Structure, function and diversity of the healthy human microbiome. Nature 486, 207-214. doi: 10.1038/nature11234

Janssen, S., McDonald, D., Gonzalez, A., Navas-Molina, J. A., Jiang, L., Xu, Z. Z., et al. (2018). Phylogenetic placement of exact amplicon sequences improves associations with clinical information. mSystems 3:e00021-18. doi: 10.1128/ mSystems.00021-18

Joerger, R. D. (2003). Alternatives to antibiotics: bacteriocins, antimicrobial peptides and bacteriophages. Poultry Sci. 82, 640-647. doi: 10.1093/ps/82.4.640

Kabir, S. M. L. (2009). The role of probiotics in the poultry industry. Int. J. Mol. Sci. 10, 3531-3546. doi: 10.3390/ijms10083531

Krieg, N. R., and Holt, J. G. (1984). Bergey's Manual of Systematic Bacteriology. Baltimore, MD: Williams \& Wilkins. 
Lee, K.-W., Li, G., Lillehoj, H. S., Lee, S.-H., Jang, S. I., Babu, U. S., et al. (2011). Bacillus subtilis-based direct-fed microbials augment macrophage function in broiler chickens. Res. Vet. Sci. 91, E87-E91. doi: 10.1016/j.rvsc.2011.01.018

Levy, S. B., and Marshall, B. (2004). Antibacterial resistance worldwide: causes, challenges and responses. Nat. Med. 10, S122-S129.

Ley, R. E., Backhed, F., Turnbaugh, P., Lozupone, C. A., Knight, R. D., and Gordon, J. I. (2005). Obesity alters gut microbial ecology. PNAS 102, 11070-11075.

Lokhande, A., Ingale, S. L., Lee, S. H., Kim, J. S., Lohakare, J. D., Chae, B. J., et al. (2013). The effects of Rhodobacter capsulatus KCTC-2583 on cholesterol metabolism, egg production and quality parameters during the late laying periods in hens. Asian Austral. J. Anim. 26, 831-837. doi: 10.5713/ajas.2012. 12559

Lozupone, C., and Knight, R. (2005). UniFrac: a new phylogenetic method for comparing microbial communities. Appl. Environ. Microb. 71, 8228-8235. doi: 10.1128/aem.71.12.8228-8235.2005

Lu, J. R., Idris, U., Harmon, B., Hofacre, C., Maurer, J. J., and Lee, M. D. (2003). Diversity and succession of the intestinal bacterial community of the maturing broiler chicken. Appl. Environ. Microb. 69, 6816-6824. doi: 10.1128/aem.69.11. 6816-6824.2003

Luo, J., Zheng, A., Meng, K., Chang, W., Bai, Y., Li, K., et al. (2013). Proteome changes in the intestinal mucosa of broiler (Gallus gallus) activated by probiotic Enterococcus faecium. J. Proteom. 91, 226-241. doi: 10.1016/j.jprot.2013. 07.017

Marshall, B. M., and Levy, S. B. (2011). Food animals and antimicrobials: impacts on human health. Clin. Microbiol. Rev. 24, 718-733. doi: 10.1128/CMR.000 $02-11$

Martín-Platero, A. M., Valdivia, E., Maqueda, M., and Martínez-Bueno, M. (2007). Fast, convenient, and economical method for isolating genomic DNA from lactic acid bacteria using a modification of the protein salting-out procedure. Anal. Biochem. 366, 102-104. doi: 10.1016/j.ab.2007.03.010

Martín-Platero, A. M., Valdivia, E., Maqueda, M., and Martínez-Bueno, M. (2009). Characterization and safety evaluation of enterococci isolated from Spanish goats' milk cheeses. Int. J. Food Microbiol. 132, 24-32. doi: 10.1016/j. ijfoodmicro.2009.03.010

Martín-Platero, A. M., Valdivia, E., Ruiz-Rodríguez, M., Soler, J. J., Martín-Vivaldi, M., Maqueda, M., et al. (2006). Characterization of antimicrobial substances produced by Enterococcus faecalis MRR 10-3, isolated from the uropygial gland of the hoopoe (Upupa epops). Appl. Environ. Microb. 72, 4245-4249. doi: 10.1128/aem.02940-05

McEwen, S. A., and Fedorka-Cray, P. J. (2002). Antimicrobial use and resistance in animals. Clin. Actual Pharm. Biol. 34, S93-S106.

Miles, R. D., Butcher, G. D., Henry, P. R., and Littell, R. C. (2006). Effect of antibiotic growth promoters on broiler performance, intestinal growth parameters, and quantitative morphology. Poultry Sci. 85, 476-485. doi: 10. $1093 / \mathrm{ps} / 85.3 .476$

Nayebpor, M., Farhomand, P., and Hashemi, A. (2007). Effects of different levels of direct fed microbial (Primalac) on growth performance and humoral immune response in broiler chickens. J. Anim. Vet. Adv. 6, 1308-1313.

Nelson, J. M., Chiller, T. M., Powers, J. H., and Angulo, F. J. (2007). Fluoroquinolone-resistant Campylobacter species and the withdrawal of fluoroquinolones from use in poultry: a public health success story. Clin. Infect. Dis. 44, 977-980. doi: 10.1086/512369

Niewold, T. A. (2007). The nonantibiotic anti-inflammatory effect of antimicrobial growth promoters, the real mode of action? A hypothesis. Poultry Sci. 86, 605-609. doi: 10.1093/ps/86.4.605

Nordentoft, S., Molbak, L., Bjerrum, L., De Vylder, J., Van Immerseel, F., and Pedersen, K. (2011). The influence of the cage system and colonisation of Salmonella enteritidis on the microbial gut flora of laying hens studied by T-RFLP and 454 pyrosequencing. BMC Microbiol. 11:187. doi: 10.1186/14712180-11-187

Ogier, J.-C., and Serror, P. (2008). Safety assessment of dairy microorganisms: the Enterococcus genus. Int. J. Food Microbiol. 126, 291-301. doi: 10.1016/j. ijfoodmicro.2007.08.017

Oh, J. K., Pajarillo, E. A. B., Chae, J. P., Kim, I. H., and Kang, D.-K. (2017). Protective effects of Bacillus subtilis against Salmonella infection in the microbiome of Hy-Line Brown layers. Asian Austral J. Anim. 30, 1332-1339. doi: 10.5713/ajas.17.0063
Oksanen, J., Blanchet, F. G., Kindt, R., Legendre, P., Minchin, P. R., O’hara, R. B., et al. (2016). vegan: Community Ecology Package. R Package Version. Available at: http://cran.r-project.org (accessed December 30, 2018).

Osman, K. M., Kappell, A. D., Elhadidy, M., Elmougy, F., Abd El-Ghany, W. A., Orabi, A., et al. (2018). Poultry hatcheries as potential reservoirs for antimicrobial-resistant Escherichia coli: a risk to public health and food safety. Sci. Rep. 8:5859. doi: 10.1038/s41598-018-23962-7

Park, J. W., Jeong, J. S., Lee, S. I., and Kim, I. H. (2016). Effect of dietary supplementation with a probiotic (Enterococcus faecium) on production performance, excreta microflora, ammonia emission, and nutrient utilization in ISA brown laying hens. Poultry Sci. 95, 2829-2835. doi: 10.3382/ps/pew241

Patterson, J. A., and Burkholder, K. M. (2003). Application of prebiotics and probiotics in poultry production. Poultry Sci. 82, 627-631. doi: 10.1093/ps/82. 4.627

Reichmann Bellino, J., and Arias Nieto, W. B. (2016). Caracterización de Mercado Para la Incorporación de Comercialización de Huevo por Peso en Honduras. Tegucigalpa: Escuela Agrícola Panamericana.

Ribeiro, V. Jr., Albino, L. F. T., Rostagno, H. S., Barreto, S. L. T., Hannas, M. I., Harrington, D., et al. (2014). Effects of the dietary supplementation of Bacillus subtilis levels on performance, egg quality and excreta moisture of layers. Anim. Feed Sci. Tech. 195, 142-146. doi: 10.1016/j.anifeedsci.2014.06.001

Ruiz-Rodríguez, M., Martínez-Bueno, M., Martín-Vivaldi, M., Valdivia, E., and Soler, J. J. (2013). Bacteriocins with a broader antimicrobial spectrum prevail in enterococcal symbionts isolated from the hoopoe's uropygial gland. FEMS Microbiol. Ecol. 85, 495-502. doi: 10.1111/1574-6941.12138

Saelim, K., Sohsomboon, N., Kaewsuwan, S., and Maneerat, S. (2012). Probiotic properties of Enterococcus faecium CE5-1 producing a bacteriocin-like substance and its antagonistic effect against antibiotic-resistant enterococci in vitro. Czech J. Anim. Sci. 57, 529-539. doi: 10.17221/6386-cjas

Sakai, Y., Tsukahara, T., Bukawa, W., Matsubara, N., and Ushida, K. (2006). Cell preparation of Enterococcus faecalis strain EC-12 prevents vancomycinresistant enterococci colonization in the cecum of newly hatched chicks. Poultry Sci. 85, 273-277. doi: 10.1093/ps/85.2.273

Salim, H. M., Kang, H. K., Akter, N., Kim, D. W., Kim, J. H., Kim, M. J., et al. (2013). Supplementation of direct-fed microbials as an alternative to antibiotic on growth performance, immune response, cecal microbial population, and ileal morphology of broiler chickens. Poultry Sci. 92, 2084-2090. doi: 10.3382/ ps.2012-02947

Schleifer, K. H., and Kilpper-Bälz, R. (1984). Transfer of Streptococcus faecalis and Streptococcus faecium to the genus Enterococcus nom. Rev. as. Enterococcus faecalis comb. nov. and Enterococcus faecium cob. nov. Int. J. Syst. Bacteriol. 34, 31-34. doi: 10.1099/00207713-34-1-31

Singer, R. S., and Hofacre, C. L. (2006). Potential impacts of antibiotic use in poultry production. Avian. Dis. 50, 161-172. doi: 10.1637/7569-033106r.1

Singh, S., Yadav, A. S., Singh, S. M., and Bharti, P. (2010). Prevalence of Salmonella in chicken eggs collected from poultry farms and marketing channels and their antimicrobial resistance. Food Res. Int. 43, 2027-2030. doi: 10.1016/j.foodres. 2010.06 .001

Souza, R. (2008). La Comercialización de los Huevos. Selecciones Avicolas: Reus

Tagg, J. R., and Mcgiven, A. R. (1971). Assay system for bacteriocins. Appl. Microbiol. 21:943.

Teuber, M. (2001). Veterinary use and antibiotic resistance. Curr. Opin. Microbiol. 4, 493-499. doi: 10.1016/s1369-5274(00)00241-1

Thibodeau, A., Topp, E., Diarra, M. S., Houde, A., Guevremont, E., Quessy, S., et al. (2007). Antibiotic resistance in Escherichia coli and Enterococcus spp. obtained from commercial broiler chickens receiving growth-promoting doses of bacitracin or virginiamycin. Can. J. Vet. Res. 72, 129-136.

Thomas, C. M., and Versalovic, J. (2010). Probiotics-host communication: modulation of signaling pathways in the intestine. Gut Microbes 1, 148-163. doi: $10.4161 /$ gmic.1.3.11712

Torres-Henderson, C., Summers, S., Suchodolski, J., and Lappin, M. R. (2017). Effect of Enterococcus Faecium strain SF68 on gastrointestinal signs and fecal microbiome in cats administered amoxicillin-clavulanate. Top. Companion Anim. Med. 32, 104-108. doi: 10.1053/j.tcam.2017.11.002

Trmcic, A., Obermajer, T., Majhenic, A. C., Matijasic, B. B., and Rogelj, I. (2011). Competitive advantage of bacteriocinogenic strains within lactic acid bacteria consortium of raw milk cheese. Mljekarstvo 61, 26-32. 
U.S. FDA (2017). FDA Reminds Retail Establishments of Upcoming Changes to the Use of Antibiotics in Food Animals. Silver Spring, MD: U.S. Food and Drug Administration.

Van Immerseel, F., De Buck, J., Pasmans, F., Huyghebaert, G., Haesebrouck, F., and Ducatelle, R. (2004). Clostridium perfringens in poultry: an emerging threat for animal and public health. Avian. Pathol. 33, 537-549. doi: 10.1080/ 03079450400013162

Vazquez-Baeza, Y., Pirrung, M., Gonzalez, A., and Knight, R. (2013). EMPeror: a tool for visualizing high-throughput microbial community data. GigaScience 2, 16-16. doi: 10.1186/2047-217X-2-16

Velasquez, C. G., Macklin, K. S., Kumar, S., Bailey, M., Ebner, P. E., Oliver, H. F., et al. (2018). Prevalence and antimicrobial resistance patterns of Salmonella isolated from poultry farms in southeastern United States. Poultry Sci. 97, 2144-2152. doi: 10.3382/ps/pex449

Wang, Y., Du, W., Lei, K., Wang, B., Wang, Y., Zhou, Y., et al. (2017). Effects of dietary Bacillus licheniformis on gut physical barrier, immunity, and reproductive hormones of laying hens. Probiotics Antimicrob. Proteins 9, 292-299. doi: 10.1007/s12602-017-9252-3

Waters, S. M., Murphy, R. A., and Power, R. F. G. (2005). Assessment of the effects of nurmi-type cultures and a defined probiotic preparation on a Salmonella typhimurium 29E challenge in vivo. J. Food Protect. 68, 1222-1227. doi: 10. 4315/0362-028x-68.6.1222

Wealleans, A. L., Li, W., Romero, L. F., Mathis, G., and Lumpkins, B. (2018). Performance and cost-benefit improvements following supplementation with a combination of direct-fed microbials and enzymes to broiler chickens raised with or without ionophores. J. Appl. Poultry Res. 27, 23-32. doi: 10.3382/japr/ pfx036

Wegener, H. C. (2003). Antibiotics in animal feed and their role in resistance development. Curr. Opin. Microbiol. 6, 439-445. doi: 10.1016/j.mib.2003. 09.009

Whitaker, R. H. (1972). Evolution and measurement of species diversity. Taxon 21, 213-251.

World Health Organization (2018). Antimicrobial Resistance. Geneva: World Health Organization.
Yang, J. H., Bhargava, P., Mccloskey, D., Mao, N., Palsson, B. O., and Collins, J. J. (2017). Antibiotic-induced changes to the host metabolic environment inhibit drug efficacy and alter immune function. Cell Host Microbe 22, 757-765.e3. doi: 10.1016/j.chom.2017.10.020

Zakowska-Biemans, S., and Tekien, A. (2017). Free range, organic? polish consumers preferences regarding information on farming system and nutritional enhancement of eggs: a discrete choice based experiment. Sustainability 9:1999. doi: 10.3390/su91 11999

Zhang, J. L., Xie, Q. M., Ji, J., Yang, W. H., Wu, Y. B., Li, C., et al. (2012). Different combinations of probiotics improve the production performance, egg quality, and immune response of layer hens. Poultry Sci. 91, 2755-2760. doi: 10.3382/ps.2012-02339

Zhao, X., Guo, Y., Guo, S., and Tan, J. (2013). Effects of Clostridium butyricum and Enterococcus faecium on growth performance, lipid metabolism, and cecal microbiota of broiler chickens. Appl. Microbiol. Biotechnol. 97, 6477-6488. doi: 10.1007/s00253-013-4970-2

Zheng, A., Luo, J., Meng, K., Li, J., Bryden, W. L., Chang, W., et al. (2016). Probiotic (Enterococcus faecium) induced responses of the hepatic proteome improves metabolic efficiency of broiler chickens (Gallus gallus). BMC Genom. 17:89. doi: 10.1186/s12864-016-2371-5

Conflict of Interest Statement: The authors declare that the research was conducted in the absence of any commercial or financial relationships that could be construed as a potential conflict of interest.

Copyright (C) 2019 Peralta-Sánchez, Martín-Platero, Ariza-Romero, Rabelo-Ruiz, Zurita-González, Baños, Rodríguez-Ruano, Maqueda, Valdivia and MartínezBueno. This is an open-access article distributed under the terms of the Creative Commons Attribution License (CC BY). The use, distribution or reproduction in other forums is permitted, provided the original author(s) and the copyright owner(s) are credited and that the original publication in this journal is cited, in accordance with accepted academic practice. No use, distribution or reproduction is permitted which does not comply with these terms. 